\title{
PESQUISA-INTERVENÇÃO: NAS MALHAS DO DESCONHECIDO - UMA EXPERIÊNCIA DE TRANSICIONALIDADE NO ESPAÇO ESCOLAR
}

\author{
Sonia Borges Cardos de Oliveira* \\ Lucia Rabello de Castro**
}

\section{Resumo}

Este artigo tem como objetivo focalizar um dos aspectos do desenvolvimento de um trabalho realizado em uma escola da Zona Sul da cidade do Rio de Janeiro, com três turmas de jovens entre 14 e 16 anos de idade, tomando como contorno analítico a importância da não neutralidade do pesquisador e sua consequente influência para a percepção das demandas grupais e qualificação das possibilidades da expressão criativa com vistas ao reconhecimento do outro e facilitação do processo de elaboração da relação com o mundo externo. Nesse sentido, elegemos como viés a explanação de um dos cincos momentos do trabalho em questão, qual seja, o que trata especificamente do "fazer coletivo", experienciado através de um "fazer criativo". As ideias de D. W. Winnicott encontram aqui significação especial, principalmente no que tange aos seus conceitos "Objetos transicionais e fenômenos transicionais".

Palavras-chave: jovens; escola; ação criativa.

\section{Abstract \\ RESEARCH-INTERVENTION: IN THE MIDST OF THE UNKNOWN - AN EXPERIMENT IN TRANSITIONALITY IN SCHOOLS \\ This article focuses on one of the aspects of a project carried out in a school located in the South Zone of the city of Rio de Janeiro, with three groups of young people between 14 and 16}

* Psicóloga; Doutoranda do Programa de Pós-graduação em Psicologia da Universidade Federal do Rio de Janeiro (UFRJ).

** Professora Titular do Departamento de Psicologia Clínica do Instituto de Psicologia da Universidade Federal do Rio do Janeiro (UFRJ) e professora do Programa de Pós-graduação em Psicologia desse mesmo instituto. 
years of age, taking as its analytical outline the importance of the researcher's non-neutrality and his / her consequent influence in the perception of group demands and in the qualification of the possibilities for creative expression, with a view towards the recognition of the other and the facilitation of the process of elaboration of the relationship with the external world. Thus, we choose as our viewpoint the explanation of one of the five moments of the project in question, which is to say, that which is specifically related to the "collective doing", experienced through a "creative doing". The ideas of D. W. Winnicott have special significance here, mainly regarding his concepts of "Transitional objects and transitional phenomena".

Keywords: youth; school; creative action.

Este trabalho traz, em seu cerne, a importância da pesquisa-intervenção como instrumento de facilitação da criação de espaços de fala e discussão entre os jovens no espaço escolar ${ }^{1}$. Assim, nossa proposta aqui é descrever como o trabalho desenvolvido com três turmas de jovens da $8^{a}$ série, durante seis meses em uma escola, entrecortado por distâncias temporais significativas entre um encontro e outro, pode ser compreendido hoje. A sustentação no tempo em que o trabalho se deu e a forma como se deu - pôde ser reportada a um ambiente de holding. Esse conceito de Winnicott ([1960] 1983), que originariamente se refere à capacidade e sensibilidade da mãe de atender, satisfazer as necessidades do bebê, representando não somente o segurar físico, mas também a provisão ambiental referente aos cuidados maternos, constitui-se fundante para o desenvolvimento, tanto físico quanto psicológico, do lactante. Inspirado nessa noção, "sustentar" aqui se refere, portanto, às seguintes significações: impedir que caia, suportar, apoiar, que, olhando à distância do período em que o trabalho foi realizado, constituíram-se uma das principais ferramentas para estar ao lado dos jovens, apoiando-os a atravessarem as dificuldades encontradas durante o exercício da "palavra compartilhada". Foi através do "fazer coletivo", como resposta à demanda dos jovens de realizarem um projeto juntos - experienciado através de um "fazer criativo" -, que "o fazer coletivo" permitiu que o que antes fora difícil, através das narrativas pessoais, pudesse constituir uma outra forma de mostrarem como se viam, como viam o outro e como viam o mundo à sua volta.

A fim de chegarmos ao tema proposto no enunciado, estruturamos nossa apresentação em três tópicos que se intercomunicam: o primeiro, uma explanação sobre como compreendemos a pesquisa-intervenção e o lugar do pesquisador em sua condição de não neutralidade, com vistas à percepção das demandas grupais e qualificação das possibilidades da expressão criativa; o segundo, breve histórico de como se deu a parceria entre o Núcleo Interdisciplinar de Pesquisa e Intercâm- 
bio para a Infância e Adolescência Contemporâneas - NIPIAC, realizador do projeto com os jovens e a instituição escolar onde o trabalho foi desenvolvido; e o terceiro, a apresentação do trabalho com os jovens, buscando alinhavar brevemente os encontros que contornaram o que estamos denominando "uma experiência de transicionalidade". Dentre outros autores, no que concerne a este último tópico, teremos como referência analítica as ideias de D. W. Winnicott e autores que dialogam com o seu pensamento.

\section{A PESQUISA-INTERVENÇÃO E O TERRENO DO DESCONHECIDO}

Pensar a pesquisa-intervenção a partir da etimologia do termo "intervenção", como nos convidam Szymansky e Cury (2004), diferenciando-o de seu sentido mais conhecido - como aquele que reporta à ação autoritária e impeditiva da livre expressão -, leva-nos à palavra "interpor". Interpor induz à ideia "de permeio", ou seja, o que se dá "entre pessoas ou coisas, no meio" (Aurélio, versão eletrônica XXI 3.0). Nesse sentido, entendemos que o estar entre, o acontecer, como sendo o que se dá entre pessoas, traz um outro significado para o termo "intervenção" quando pensamos na modalidade da pesquisa-intervenção, especificamente com crianças e jovens. $\mathrm{O}$ estar entre pressupóe que pesquisadores e adolescentes - usualmente marcados no cotidiano da pesquisa pelo distanciamento demarcado pelas posições identitárias de "pesquisador" e "adolescente", como coloca Castro (2003) encontram-se permeados por algo que lhes é comum. E o que é comum é justamente o que está entre, o que não se sabe, e que tomará corpo no processo mesmo de uma construção conjunta, em que pesquisador e adolescentes tecerão novos significados para o que se pretende investigar.

Essa perspectiva do "não saber" afina-se como oposição às construções de saberes sobre os jovens em que estes são "traduzidos pelos adultos" (Castro, 2008). De modo contrário, nosso trabalho tem-se pautado pela inserção no campo da pesquisa com crianças e adolescentes a partir da concepção que os qualifica como parte integrante do processo de pesquisa. Nessa perspectiva, como assinala Castro (2003: 4), ao adentrarmos seus espaços, "não somos nós, pesquisadores, que estamos contando sobre os adolescentes, mas que somos também contados por eles. São eles que nos atingem, multiplicando e diversificando as experiências do estar junto e dialogar". Assim, o pesquisador "não se coloca fora do processo de pesquisa, como um ator que não 'contamina' o processo, mas um ator de quem depende a continuação do processo que é marcado por sua presença e por sua ação" (Castro, 2008: 27). 
Nesse sentido, o pesquisador, ao entrar em campo, depara-se com a confluência que se estabelece por esses lugares de enunciação e seus desdobramentos: por um lado, ao entrar em campo, carrega consigo os princípios (no sentido de começo, origem) norteadores da pesquisa discutidos em sua base institucional que é seu lugar de origem, de estudo, de discussão e de orientação. Lugar onde é também sustentado, apoiado, quando do retorno do campo, onde as suas dúvidas podem ser compartilhadas, desfeitas ou refeitas em outras interrogações -; e, por outro, lida com a transformação desses princípios, que são constantemente refeitos no processo mesmo da interação entre adolescente e pesquisador.

Assim, a experiência de habitar esse espaço constituído pelo "entre", pelo "interpor-se", traz-nos o "desconhecido" como o elemento "comum" que se coloca entre os sujeitos envolvidos, constituindo-se uma porta de entrada às possibilidades de vínculo entre pesquisador e adolescente, onde a igualdade se estabelece ao habitarem a mesma incerteza frente ao que está por vir. Dessa forma, o desconhecido, revelado no próprio campo da pesquisa, onde pesquisador e adolescentes são afetados pelas mútuas presenças e influências, apresenta-se como possibilidade de vir a ser denominado conhecimento. Desse modo, o pesquisador, na condição de não neutralidade, provê uma abertura à percepção das demandas dos grupos com os quais trabalha e suas possibilidades de expressão criativa, que estarão em consonância não com o que é sabido, mas, sim, criado. A criatividade, por sua vez, manifesta-se como ação frente aos obstáculos que se apresentam na realidade externa (Ortega, 2007). Esses obstáculos, no entanto, devem constar como conteúdos do próprio processo da pesquisa e refletir as condiçôes criadas naquela dada realidade, de modo que o ambiente ali estabelecido não se constitua invasivo e impeça que a espontaneidade se coloque a serviço da ação criativa, favorecendo, através dos problemas que ali se apresentarem, o experienciar do impulso necessário para uma nova ação. É justamente quando o pesquisador provê a expressão da ação, no sentido de agir e não de reagir, que permitirá aos jovens com os quais trabalha trazer para seu campo de experimentação uma forma de expressar o seu próprio sentido de ser. Nesse sentido, também a percepção do pesquisador imprime ao processo de pesquisa uma forma de ação criativa, pois a percepção é também uma ação relacionada à criatividade, como observa Ortega (2007) ao reler Winnicott: "Existe uma relação estreita, quase uma identificação, entre percepção e criatividade. Perceber é olhar criativamente o mundo, estabelecer uma continuidade com ele" (Ortega, 2007: 135).

Entendemos, portanto, que, no âmbito da pesquisa-intervenção, essa continuidade se dá em conformação com toda uma atitude em campo que permite, tanto a pesquisadores quanto a adolescentes, a disponibilidade de navegarem no 
"turbilhão de incertezas e curiosidades" (Szymansky \& Cury, 2004) que perfazem o caminho do encontro nessa área "desconhecida", onde pesquisador e adolescentes terão a oportunidade de tecer novos significados para os fenômenos que ali se apresentarem.

\section{ParCeria COM A INSTITUIÇÃo: ASSERÇÃo SOBRE UM MODO DE CONTINUIDADE}

O trabalho ao qual nos referimos inicialmente ocorreu em uma escola da Zona Sul da cidade do Rio de Janeiro, com três turmas de jovens da $8^{a}$ série, com idades de 13 e 14 anos, durante o segundo semestre de 2003. No entanto, a parceria com essa instituição escolar remonta ao ano de 2001, o que, a nosso ver, expressa não só a manutenção no tempo da relação estabelecida entre as duas partes como também encontra significação especial ao olharmos o percurso do trabalho nessa instituição e percebermos que, ao longo de três anos, houve um avanço no modo da colaboração estabelecida.

Em 2001, o Núcleo Interdisciplinar de Pesquisa e Intercâmbio para a Infância e Adolescência Contemporâneas (NIPIAC) dava andamento ao subprojeto Cidade em Imagens, que comportou, a partir da elaboração de três vídeos didáticos produzidos pelo próprio núcleo de pesquisa, grupos de discussão com crianças, jovens e adultos sobre o viver na cidade. Foi em uma dessas apresentaçôes, dirigidas às Associaçôes de Moradores da cidade do Rio de Janeiro, que a escola teve o primeiro contato com os trabalhos desenvolvidos pelo núcleo de pesquisa citado. A partir desse primeiro contato, três subprojetos foram realizados na escola: Oficinas da Cidade 2 em 2001, Cidade em Imagens, em 2002, e Jovens pelos Jovens, em 2003. Como o primeiro projeto realizou-se fora do horário escolar, avaliamos que essa modalidade não facilitava a adesão do aluno, assinalando a desvinculação do projeto dentro da instituição. Assim, o projeto seguinte foi desenvolvido dentro da grade do horário escolar, com turmas da $8^{a}$ série. Ao ser finalizado, a escola solicitou a continuidade do trabalho, sugerindo a criação de outro instrumento de mobilização e discussão com os jovens. Após acertarmos um formato que lhe permitisse estar mais implicada no desenvolvimento do próximo projeto, em 2003 demos andamento ao subprojeto Jovens pelos Jovens ${ }^{3}$, proposto à instituição com o objetivo de criar um espaço de discussão e reflexão dos jovens em seu espaço de estudo. Assim, tanto o núcleo de pesquisa quanto a instituição mobilizaram-se para uma nova produção, sustentada por ambas as partes em favor da continuidade do projeto. 
Para tanto, foram apresentados textos preparados por jovens universitários, com conteúdos oriundos de resultados de outras pesquisas, que tratavam de temas afins a esse cotidiano. Após as discussōes, o objetivo era que os jovens elegessem uma forma própria de expressarem os conteúdos discutidos. Quanto à implicação da escola, a instituição compreendeu-a a partir da participação dos professores durante os grupos de discussão. A equipe de pesquisa, no entanto, avaliou que a proposta, para constituir uma parceria e dar sentido à presença dos professores durante os grupos de discussão, deveria ser entendida como um trabalho que poderia ser aproveitado pelos professores ao associarem os temas ali discutidos aos conteúdos desenvolvidos em suas aulas. Assim, o projeto teve início com a participação de quatro professores, que, a cada encontro, cederiam dois tempos de suas aulas para a realização do projeto.

O trabalho se deu "sustentado" em quatro pilares: as pesquisadoras traziam para o campo a referência de uma história com a instituição. Ainda que essa, muitas vezes, tenha se apresentado frágil enquanto suporte, pontuava um reinício em um lugar já existente, o que representava certa dimensão de continuidade, constituindo, dessa forma, uma referência; as discussões das pesquisadoras em seu núcleo de pesquisa, sua base institucional, onde eram apoiadas quando do retorno do campo, compartilhando suas dúvidas, desfazendo-as ou refazendo-as em outras interrogações; os encontros entre pesquisadoras, coordenação escolar e os professores envolvidos no projeto, em que o andamento do trabalho era discutido e os conflitos e as tensôes durante o desenvolvimento dele eram redimensionados; e, por fim, a relação entre as pesquisadoras (coordenadoras de atividade) e os jovens, que, ao estabelecer um ambiente de "confiança e fidedignidade" (Winnicott, [1971a] 1975: 150), permitiu que um determinado espaço, constituído pela distância entre o que se esperava que pudesse ocorrer e o que eles manifestaram como sendo o seu desejo "de um fazer", se convertesse em um espaço de transicionalidade.

\section{FENÔMENOS E OBJETOS TRANSICIONAIS: UMA TEORIA WINNICOTTIANA}

Assim como alguns adultos fazem amigos e inimigos no trabalho, enquanto outros ficam sentados esperando anos a fio, não tendo nada a fazer senão admirarem-se de ninguém querê-los, as crianças fazem amigos e inimigos ao brincarem, mas não fazem facilmente amigos fora do brincar. $\mathrm{O}$ brincar oferece a organização para o início das relações emocionais, possibilitando que os contatos sociais aconteçam (Winnicott, citado por Abram, 2000: 262). 
Em O lugar em que vivemos, Winnicott ([1971a] 1975]) coloca-se entre dois extremos do viver humano, entre o comportamento "no mundo da realidade externa (ou compartilhada)" e a vida interior, para examinar o "lugar" em que nos encontramos quando experimentamos o "viver" enquanto ouvimos uma música, admiramos uma pintura, lemos algo que nos entretém, ou quando uma criança brinca no chão na presença da mãe, ou, ainda, quando um grupo de adolescentes se reúne para ouvir ou fazer música. Direciona sua busca com a seguinte observação:

Tento colocar-me entre esses dois extremos. Se examinarmos nossas vidas, provavelmente descobriremos que passamos a maior parte de nosso tempo nem em comportamento nem em contemplação, mas em outro lugar. Pergunto: onde? [...]

Não é apenas: o que estamos fazendo? É necessário também formular a pergunta: onde estamos (se é que estamos em algum lugar)? Já utilizamos os conceitos de interno e externo e desejamos um terceiro conceito. Onde estamos, quando fazemos o que, na verdade, fazemos grande parte de nosso tempo, a saber, divertindo-nos? (Winnicott, [1971a] 1975: 146-147).

A resposta de Winnicott é que existe um "lugar", um "viver" em nossas vidas, que não trata nem do mundo interno, realidade psíquica, nem do mundo externo, realidade compartilhada, mas, sim, da "terceira área da existência" (Winnicott, [1959] 1994]: 47), que "constitui uma área intermediária de experimentação, para a qual contribuem tanto a realidade interna quanto a vida externa" (Winnicott, [1971b] 1975: 15). Essa área, afirma, não deverá ser disputada nem contestada, pois nenhum interesse ou reivindicação é feito(a) em seu nome, "exceto que ela exista como lugar de repouso para o indivíduo empenhado na perpétua tarefa humana de manter as realidades interna e externa separadas, ainda que inter-relacionadas" (idem; grifo nosso).

É nessa área que ocorre o que o autor denominou fenômenos transicionais, que estão relacionados, na vida de todo indivíduo, aos primórdios de seu desenvolvimento. Referem-se à transição do estado de fusão mãe-bebê ao estado em que a mãe possibilitou ao bebê - a partir da sua capacidade especial de se adaptar e atender às suas necessidades - a experiência da ilusão de criá-la (o seio), ao estado em que este passa a percebê-la objetivamente como algo separado dele, ou seja, como uma pessoa "não eu". Nesse processo, o bebê criará e adotará um objeto "não eu", o objeto transicional, que será sua "primeira possessão", como define Winnicott ([1971b] 1975: 17), e com o qual e através do qual estará envolvido em sua tarefa de relacionar as realidades interna e externa: o objeto criado é ama- 
do, mas também mutilado, recriado e acariciado, dá-lhe calor, é vivo para o bebê e a ele sobrevive. Embora seja um objeto externo, real, concreto e observável do ponto de vista do observador, para o bebê ele não é externo nem interno, "mas um símbolo, um veículo, que tanto pode reapresentar ele mesmo como a mãe, e lhe possibilita uma transição de um sentido de realidade para outro", ou seja, "trata-se de um movimento em que o objeto transicional possibilita a viagem do subjetivo à realidade compartilhada" (Safra, 2005: s/p).

Essa viagem se dá na área intermediária, que, na tenra infância, como afirma Winnicott ([1971b] 1975: 29), "é necessária para o início de um relacionamento entre a criança e o mundo...”. Essa passagem para o mundo é também explicitada em seu argumento quando diz que "o termo objeto transicional, segundo minha sugestão, abre campo ao processo de tornar-se capaz de aceitar diferença e similaridade" (ibid.: 19). Enquanto primeira posse, o objeto transicional, ao ser gradativamente descatexizado, vai perdendo significado para se expandir em significação nas experiências culturais, disseminando-se por todo o território intermediário em que nos havemos com a eterna tarefa de relacionar as realidades interna e a externa. Encontramo-nos aí, nessa área intermediária, quando experimentamos o viver criativo, que não diz respeito a nada que alguém possa dizer ser especial, a não ser para quem o vive e que é tão simples, como diz Winnicott, como o respirar. Algo que diz respeito às artes - mas não a uma obra de arte a interpretar e, sim, ao processo de criá-la -, "à religião, ao viver imaginativo e ao trabalho científico criador" (ibid.: 30). Ao empregar o termo "experiência cultural", Winnicott ([1971c] 1975: 138) diz não estar certo de "poder definir a palavra cultura", mas salienta a "experiência cultural" como uma ampliação da ideia dos fenômenos transicionais e da brincadeira, em que a ênfase recai na experiência.

\section{UMA EXPERIÊNCIA DE TRANSICIONALIDADE NO ESPAÇO ESCOLAR}

O terceiro dos cinco encontros que realizamos com as três turmas de jovens da $8^{a}$ série, compostos por uma média de 21 alunos, situou-se como um dos pontos mais significativos do campo de trabalho com os jovens naqueles seis meses de 2003. Como uma ponte imaginária situada entre os dois primeiros e os dois últimos encontros, o terceiro encontro, o qual denominamos Confecção de cartazes e "o fazer coletivo", permitiu-nos transitar entre os acontecimentos produzidos no início do trabalho e no final dele, para significá-lo como um trabalho em que se deu "uma experiência de transicionalidade no espaço escolar". 
Antes de chegarmos ao terceiro encontro, convidamos o leitor a também transitar pelas experiências que contornaram aquela que estamos denominando transicionalidade. Passaremos brevemente pelos dois encontros iniciais e nos deteremos um pouco mais no terceiro, finalizando com as considerações que se inserem na conclusão do trabalho propriamente dito. Para melhor acompanhamento dos relatos, utilizaremos como referência as seguintes designações: Turma "A", Turma "B" e Turma "C". Usaremos a letra " $\mathrm{D}$ " como indicação da professora que acompanhou todo o projeto. As falas dos jovens e da professora serão transcritas em itálico para se distinguirem dos relatos das coordenadoras de atividade.

No primeiro encontro, apresentamos para eles o texto Qual é? Tá me estranhando? ${ }^{24}$, sobre a estranheza do viver em uma cidade grande e de como a diversidade de sua apreensão faz emergir no dia-a-dia a estranheza em relação ao outro. O texto fala também de desprezo, insensibilidade e medo, assim como de preocupação, cuidado e acolhimento. A proposta era que, após a leitura, os jovens discutissem os temas abordados e pudessem pensar na sua relação com o outro a partir das suas reflexões. Em seguida, supôs-se que eles pudessem criar um instrumento de expressão que lhes possibilitasse mostrar a própria versão sobre os temas abordados: poderia ser através de outro texto, vídeo ou qualquer outra ferramenta que escolhessem. Mas essa proposição foi-se modificando ao longo do trabalho.

Durante a leitura do texto, muitos se sentiram intimidados pela "zoação" dos colegas, de forma que, no decorrer do trabalho, o "zoar" foi perdendo a sua característica de brincadeira para se configurar em uma forma de ridicularizar e ser intolerante com o outro, obstruindo muitas vezes o desejo de participação. Em todas as turmas, o "zoar" foi associado à diversão e, na maioria das vezes, expressado através da objetificação e desqualificação do outro, como atesta o relato de uma das coordenadoras que encaminhou o trabalho:

Outro assunto que surgiu foi relacionado com as agressões, de que muitos admitiram já terem praticado, e os que diziam não terem feito afirmavam que conheciam quem já o tivesse. Então, o grupo começou a pensar o que levaria as pessoas a agredirem determinadas pessoas, como as prostitutas e os homossexuais citados no texto, e chegou à rápida conclusão de que é a exposição dessas figuras na rua, lugar muito perigoso, e, se estavam ali, sabiam do risco que corriam. Disseram haver outras formas de agressão, como a do extintor, na qual chama-se uma prostituta para perto do carro e liga-se o extintor na cara dela. Outro menino disse que alguns de seus amigos brincam de "estourar silicone de puta". Quando perguntei como era isso, ele respondeu: "Eles se aproximam das prostitutas, com um soco-inglês na mão, e enrolam a mão em uma camisa para que 
as putas não vejam o que eles têm na mão, e, quando se aproximam delas, eles dão um socão nelas, estourando o silicone”. Perguntei o que eles achavam dessa prática e eles disseram que era só diversão (Turma “C”).

Ao olharmos as cenas descritas nos relatos acima, certamente nos sentimos afetados pelo descaso em relação ao outro, mas queremos focar outra perspectiva. Seus protagonistas, jovens de classes média e média alta, ao percorrerem as ruas da cidade em busca de diversão, emprestam-nos uma das faces que o contemporâneo nos apresenta: espaços vazios de civilidade, com indivíduos voltados cada vez mais para si próprios, sinalizando-nos a premência de nos confrontarmos com a indiferença produzida em nossos dias. Desse modo, o que o relato nos mostra é o fato de ter podido haver, no âmbito escolar, um "lugar" para se mostrar no mundo, sinalizando a necessidade de nos havermos com nossos próprios sentimentos para que pudéssemos estar "ali", sustentando o inimaginável, para que algo pudesse ocorrer, se tivesse de ocorrer, "na presença de alguém" - alusão à observação de Winnicott ([1958] 1983) em A capacidade para estar só.

No segundo encontro, o estranho, enquanto aquele que é diferente, apareceu dentro do próprio grupo, confrontando-o com a alteridade à medida que a ideia de homogeneidade foi-se desfazendo, como se não houvesse diferença entre eles, ou, se houvesse, esta fosse bem tolerada. A proposta era dar continuidade às discussões em grupo após a leitura de outro texto. E ai, com quem você anda? foi o texto apresentado. $\mathrm{O}$ texto pergunta se, pelo fato de vivermos em uma cidade grande, como o Rio de Janeiro, na qual muitas vezes nos sentimos sozinhos, pertencer a um grupo não seria uma forma de nos sentirmos acolhidos. No decorrer desse encontro, hostilidade, ódio e indiferença se expressaram como sentimentos e reaçôes defensivas para lidar com a alteridade, quando as diferenças começaram a aparecer, confrontando-os, assim, com o medo de não serem aceitos em suas singularidades.

Nesse encontro, dois eventos determinaram a mudança de percurso do trabalho: a saída de três professores e a proposta dos jovens para que mudássemos a dinâmica do trabalho. Dos quatro professores que iniciaram o trabalho, apenas um permaneceu até a sua finalização. Após avaliarmos os impactos provocados nos professores diante dos relatos dos alunos ocorridos no primeiro encontro, consideramos que o trabalho seria inviabilizado se os professores estivessem ameaçados pelo que os alunos falavam. Não nos ficou claro, no entanto, se o afastamento de três dos quatro professores correspondeu somente à incompatibilidade de horário ou à dificuldade de lidar com o conteúdo discursivo dos jovens que emergia durante os grupos de discussão. A professora de História, 
que permaneceu até a finalização, esteve desde o início vinculada ao projeto, participando da sua elaboração com a escola e a equipe de pesquisa, tornandose o elo entre esta e a escola, vislumbrando, desde o início, outras respostas dos jovens, como a linguagem artística ou musical. Com relação à solicitação dos jovens, consideramos importante criar um instrumento de trabalho que facilitasse a expressão e a participação e que respondesse às suas demandas para realizar algo mais concreto e dinâmico.

Para o terceiro encontro, decidimos, então, como metodologia de trabalho, que apresentaríamos recortes de revistas com figuras diversas para que os jovens produzissem cartazes em grupo, através dos quais iriam expressar o que eles pensavam sobre grupos, reais ou imaginários, de que gostassem ou não e que gostariam que houvesse. Assim, através de colagem, desenhos ou escrita, construiriam a versão da história deles sobre como são esses grupos e como vivem na cidade do Rio de Janeiro, exercitando a imaginação com vistas a compreenderem a própria vivência na cidade e suas escolhas para a convivência no espaço urbano. O tema "grupos" foi o escolhido por ter mobilizado a maioria dos jovens.

A tarefa da produção dos cartazes pareceu "acalmar" a angústia que se apresentou nos momentos em que tinham que se colocar diante dos colegas. Assim, o "fazer junto" teve a função de uma produção coletiva que, diferente dos momentos em que expuseram sozinhos as suas opiniōes, permitiu que as associações e simbolizaçôes pudessem se dar na cumplicidade de um fazer criativo, no qual as colagens das figuras, os desenhos e as frases, enfim, cumpriram o papel de intermediário entre a realidade interna e a realidade externa. Foi nesse encontro que a "experiência de transicionalidade" pareceu significativa, reportando-se aos conceitos Objetos transicionais e fenômenos transicionais, de Winnicott ([1971b] 1975), nos quais o fazer criativo, que se dá na "terceira área da existência", possibilita o contato com a realidade externa. Mas a criatividade para Winnicott "não vem de dentro do indivíduo, não é um evento de seu mundo interior; ela acontece entre dois ou mais indivíduos, na interação de indivíduo e ambiente no espaço transicional; é externalizada" (Ortega, 2007: 129).

Dessa forma, durante o processo de confecção de cartazes, as figuras de "objetos do mundo" foram tomadas por cada um, compartilhadas entre seus pares e "usadas" durante o processo criativo. Olhando, "microscopicamente", para o momento em que estavam criando, podemos dizer que não importava muito o sentido que dariam àquelas figuras, mas, sim, que ali, naquele "espaço potencial" (Winnicott, [1971d] 1975: 79), que se deu "entre" adolescentes e pesquisadoras, "havia um lugar" onde eles podiam estar. Junto a seus pares, puderam estar sozinhos em suas fantasias, criando "suas realidades", "seus outros sentidos". 
Esse momento de "descanso", que se dá nessa "área intermediária de experimentação”, pôde ocorrer porque havíamos construído um ambiente de confiança desde os primeiros encontros, um holding, por assim dizer. Assim, ao não nos abatermos ou agirmos de modo intrusivo quando os jovens expressavam seus sentimentos e faziam seus relatos e ao termos atendido à solicitação de poderem se expressar de outra maneira - longe do receio de não serem ouvidos, não poderem falar, serem ridicularizados e/ou ridicularizarem o outro -, o ambiente de confiança se expressou ao provermos um espaço em que puderam se experimentar e "ser" através de um "fazer".

Um dos aspectos importantes da teoria da ação criativa de Winnicott, apontado por Ortega (2007), é que o impulso agressivo-criativo (espontâneo) depende da quantidade de resistência encontrada para ser experienciado: "Para Winnicott, o indivíduo tem uma relação ativa com o ambiente, age sobre ele transformandoo e ao mesmo tempo modificando-se a si próprio" (Ortega, 2007: 130). Por outro lado, assinala:

se a quantidade de oposição do ambiente de que o indivíduo precisa para experienciar sua criatividade e sentir-se real não é suficiente, ou é tão forte que se apresenta como uma intrusão que exige a reação do indivíduo, em ambos os casos o resultado é a doença, a perda de sentimento de realidade e ruptura da continuidade da existência (Ortega, 2007: 131).

Entendemos, assim, que a proposta dos jovens de fazer algo mais concreto correspondeu a uma ação e não a uma reação. A proposta anterior, de leitura de texto, discussão em grupo e criação de uma versão deles sobre o que haviam compreendido, colocou-se como uma "resistência", algo com que tiveram que se haver, levando-os a um "outro agir". Nesse processo, pudemos perceber o que nos diz Ortega (2007) a respeito da apreciação de Axel Honneth sobre a criatividade, quando menciona que esse autor "assinala a conexão fundamental entre criatividade e reconhecimento, já que a criatividade acontece sempre entre dois ou mais indivíduos e implica o reconhecimento do outro como não eu e diferente de mim, como parceiro no brincar, na experiência criativa” (Ortega, 2007: 129).

Em média, os jovens produziram cinco cartazes em cada turma, dos quais ilustraremos apenas dois. À medida que trouxermos parte de seu conteúdo, descreveremos como se deu a apresentação deste, que constou como atividade do quarto encontro.

O primeiro grupo que se apresentou em uma das turmas foi um grupo composto só por meninas. Compenetradas, foram em quatro apresentar o trabalho. $\mathrm{O}$ 
título era: "Grupos?". Meio tímidas, mostraram os grupos que se uniam por interesses comuns: os de consumidores que foram representados por vários objetos da moda e de uso pessoal; os músicos, os esportistas, os gays, os nerds; os que se uniam pela religião ou pelo interesse na ecologia; as prostitutas e outros. No início, consideraram os grupos como fechados, que foi como confeccionaram o cartaz. Ao longo da apresentação, mostraram-se mais reflexivas com as perguntas dos colegas e o questionamento da professora. Consideraram que primeiramente era assim mesmo, o que unia as pessoas eram interesses comuns, mas que depois as pessoas podiam se misturar. O grupo perguntou sobre algumas figuras de pessoas que se encontravam soltas, ou seja, sem grupo. Primeiramente disseram que não era nada, depois uma das colegas, fora do grupo de apresentação, contribuiu dizendo que aqueles eram os excluídos, os que não pertenciam a grupo algum. Outra colega complementou dizendo que talvez aquelas pessoas, na verdade, não fossem excluídas, mas se excluíssem. Essa sua fala esteve presente nas discussões sobre o texto e parecia assegurar que não era ela que excluía ou que tinha preconceito, mas, sim, o outro é que era responsável por sua condição de excluído. Mas, de qualquer modo, essa era a segunda vez em que L. pareceu refletir sobre a relação entre preconceito e exclusão.

Em outro grupo, o jovem que apresentou o cartaz estava sozinho. Foi o único presente, de seu grupo de três componentes, na apresentação dos cartazes. Esse foi um dos grupos que apresentou a dinâmica mais difícil durante o encontro anterior. Um dos componentes era muito agitado, não deixava nem o seu grupo nem os outros trabalhar. Falávamos com ele, ele se acalmava um pouco, mas, depois, retornava em seu movimento, circulando entre os grupos. Não podia "estar relaxado" na experiência "do criar". Como nos fala Winnicott ([1971a] 1975: 151), "o brincar e a experiência cultural são coisas que vinculam o passado, o presente e o futuro e que ocupam tempo e espaço. Exigem e obtêm nossa atenção deliberada e concentrada".

O cartaz que apresentaram "parecia" um trabalho inacabado, ainda por fazer. As figuras estavam espalhadas pela cartolina, não havia título, havia nomes rabiscados, mas havia uma ideia original. No meio desse "não tenho nada a dizer", a ideia era mostrar a turma e alguns de seus membros. R. iniciou sua apresentação falando muito baixo e jogando suas palavras fora: "Isso é isso aí... é a turma, uns colegas ai... é uma brincadeirinha que a gente fez aí com a turma, com o grupo...". Ria, com um misto de rindo do trabalho, de si próprio e da vergonha de estar ali sozinho, tendo que sustentar aquela ideia. Procuramos ajudá-lo, valorizando o trabalho para que não se caísse no deboche. Uma das coordenadoras lhe perguntou: "Como é essa ideia de representar os colegas da turma com essas figuras? O 
que elas querem dizer? Eles fazem parte de um grupo? Que grupo é esse?”. R. ganhou mais voz, tinha o que dizer, e os colegas passaram a complementar suas observaçōes. Seu trabalho começou a acontecer ali, junto aos colegas. Quando questionado por que alguns colegas eram representados por aquelas figuras, R. riu, dizendo que era só olhar para a cara deles e ver que tinha tudo a ver. Perguntamos se eles se sentiam ofendidos com aquelas figuras: uma era um cavalo de óculos que representava um dos colegas, L.; a outra tinha a cara de um animal enorme, talvez um rinoceronte; outra era a "eguinha pocotó"; outra era uma colega nissei carregando uma enorme bola. M., a colega a quem quiseram representar, identificou-se com a figura. Havia algumas figuras de bebês, bem delimitadas num círculo, que representavam os pequenos da turma. L., que era um dos representados, disse não se ofender, que aquilo era só uma brincadeira e uma maneira de falar da turma. M. complementou dizendo que aquelas figuras, assim meio disfarçadas de animais, eram só a aparência, demonstravam como as pessoas da turma se apresentavam, pois também ali, na turma, elas não podiam mostrar como de fato eram.

Seguiu-se uma discussão em torno dos disfarces. Disseram que ninguém ali se mostrava como realmente era, que se disfarçavam com máscaras. O que inicialmente poderia parecer um pouco agressivo foi acolhido pela turma como uma expressão de sentimentos antes não revelados. No final, disseram que aquele cartaz estava dizendo isso: "que eles não se mostravam como realmente eram". Ficounos a pergunta: em que outro lugar também não podiam se mostrar? O que estariam dizendo com "mostrar o que realmente eram"? Essas perguntas não foram feitas, mas talvez possamos pensar que estivessem dizendo do desejo de estarem juntos de outra forma; de poderem aceitar a possibilidade de formarem um grupo ainda que eles não fossem exatamente como os colegas esperavam; ou, talvez, que o descaso, com que tantas vezes receberam as coordenadoras, ou mesmo como muitas vezes se tratavam, pudesse se revelar como disfarce pelo temor de serem descobertos ou invadidos pela mobilização do que é desconhecido.

$\mathrm{O}$ quarto encontro, momento de apresentar os cartazes para os colegas, fez eclodir sentimentos de angústia e o temor de desaprovação. A demonstração de intolerância uns com os outros, o não poder falar e ser ridicularizado pelos colegas apresentaram-se como dos sofrimentos mais visíveis desses jovens. No entanto, ao olhar o seu percurso, foi possível perceber uma evolução do estado de descaso e desinteresse para um estado de preocupação e cuidado, o que se explicitou mais claramente no encontro seguinte.

Quanto à angústia que se apresentou nesse momento, olhando à distância, achamos que o processo esteve referido à impossibilidade de os jovens darem sig- 
nificado ao que criaram por temerem a interpretação, ou crítica, de algo que fora construído em um momento em que estavam "mergulhados" na "tarefa" de relacionarem as suas realidades interna e externa. A explicação dos cartazes talvez se tenha configurado como uma invasão àquele momento de criatividade, o que podemos aludir a uma das observações de Winnicott ([1971c] 1975) sobre a interpretação do analista como uma intrusão no "espaço potencial": "Os analistas precisam estar atentos para evitar a criação de um sentimento de confiança e uma área intermediária em que a brincadeira se possa efetuar, e, depois, injetar nessa área ou inflá-la com interpretaçôes que, com efeito, provêm de suas próprias imaginaçôes criativas" (Winnicott, [1971c] 1975: 141).

O último encontro foi dedicado ao fechamento do trabalho. Dez perguntas foram construídas para que, através de sorteio, cada membro do grupo respondesse a uma pergunta com a ajuda dos colegas. Algumas das perguntas elaboradas foram: Como foi receber alguém de fora para fazer esse trabalho?; Houve dificuldades em participar desse trabalho?; Você gostou de participar desse trabalho?; A turma construiu alguma coisa com esse trabalho?. Em cada uma das duas turmas, foram sorteadas apenas sete das perguntas elaboradas. Posteriormente, eles fizeram perguntas sobre o trabalho para as coordenadoras. Nesse encontro, alunos, coordenadoras e professora falaram sobre como perceberam e como se sentiram durante o trabalho.

Nesse encontro, que denominamos Avaliação e finalização - um novo começo, os jovens ainda "usaram" os espaços de fala para expressarem suas dores, falarem de seu ódio pelos colegas e pela escola. No entanto, ao olharmos para esse encontro, mas com o invólucro dos encontros anteriores, percebemos, através de pequenos gestos, de algumas palavras e de algumas perguntas dirigidas às coordenadoras, uma nova tessitura afetiva em relação a elas. Citamos algumas delas: Você gostou da gente? Vocês se sentiram rejeitadas pelos alunos? O desempenho dos alunos foi o esperado? Vocês vão escrever algo sobre a gente?

Em uma das turmas, perguntaram para a coordenadora se ela já havia feito esse trabalho em outros lugares e como teria sido. Quando a coordenadora explicou que já havia desenvolvido o trabalho em escolas públicas, os jovens perguntaram se os alunos da escola pública eram melhores do que eles. Percebemos que, ao perguntarem "se os alunos da escola pública eram melhores do que eles", há um texto subentendido em que se percebem de forma negativa. Um dos alunos deixa clara a sua tentativa de compreender o que se passou com eles durante o trabalho, deixando também transparecer certa preocupação com o modo como se apresentaram:

[...] então G. perguntou se fazíamos esse trabalho em escolas públicas. Disse que sim. Ele então falou: "Eles devem ser bem mais revoltados do que a gente". Pedi para 
que ele explicasse melhor: "Porque eu chego em casa, eu tenho um prato de comida, uma cama... Eles não, não têm nem professor, escola toda quebrada. Eles não devem querer fazer nada, devem ser piores do que a gente". Disse que isso depende muito de cada pessoa, de cada escola, mas que, devido a essa carência de que ele havia falado, os alunos eram bastante receptivos (Turma "B”).

Entendemos essas perguntas como sendo a forma que os jovens encontraram para dizer como se perceberam durante o trabalho e a maneira de expressar o temor de serem rejeitados pelas coordenadoras e assim não serem reconhecidos como jovens que teriam com o que contribuir.

$\mathrm{Na}$ finalização do encontro, as coordenadoras agradeceram e qualificaram a participação dos jovens e da professora. A professora "D" aproveitou para falar do trabalho e também se despedir, pois não daria mais aula para os alunos da $8^{\mathrm{a}}$ série. A professora " $D$ " falou da importância do trabalho, não só para eles, mas também para ela. Para os alunos, disse achar importantíssimo discutir assuntos atuais e de suas vidas, pois isso estava relacionado com a "História" e a forma de eles compreenderem o mundo. Em nosso último contato, que se deu no primeiro semestre de 2004, ela nos falou:

Em última instância, você vê uma relação amorosa, parece que não tem nada; depois, você vê que tem. No final, eles tiveram uma relação amorosa. Talvez esse trabalho tenha servido para reforçar esses laços. Alguns alunos que eram problemáticos, que odiavam a escola, parecem ter-se modificado. Alguns quiseram sair e depois ligaram para voltar. [...] Eu acho que eles se sentiram acolhidos, e para mim tem a ver com essa escuta.

Embora não tenhamos podido explicitar algumas de suas observações, sobre, por exemplo, como se dera, na continuidade de seus contatos com os alunos, a expressão de "amorosidade" entre eles, ou mesmo que outras variáveis possam ter influenciado o retorno dos alunos que queriam sair da escola, achamos importante a sua observação, pois, na ocasião em que nos falamos, ela já estava implicada com alunos de outras séries. O que nos chamou a atenção é que, após sete meses, em sua rememoração, ela nos falou de relação amorosa.

\section{CONSIDERAÇÕES FINAIS}

Chegamos até aqui para dizermos que, no final da realização do projeto com os jovens, creditamos a algumas palavras, a algumas frases que construíram e aos 
pequenos gestos a expressão de uma nova afetividade e de cuidado com o outro. Relendo os relatórios desses meses de trabalho ${ }^{6}$, observamos como cada uma de nós, que estivemos à frente de sua condução, percebeu a mudança que ocorria ao longo dele. Foi preciso que estivéssemos ali, sustentando cada passagem. "Estar ali” significava aceitar que nem sempre estava sendo fácil, agradável e que nem toda tentativa de neutralidade nos impediria de nos sentirmos em um terreno instável, hostil e tantas vezes indiferente. Ao contrário, isso nos impediria de percebermos as nuanças, de lermos em nossas próprias sensaçôes o que se dava à nossa volta, o que se dava entre os jovens. Poder "estar ali" significava aguardar os seus silêncios e nos oferecer de modo a não nos deixarmos abater ou querer mudar o curso que se apresentava. Significava sustentar, com todo o rigor que a palavra exige - segurar por baixo; servir de escora a; impedir que caia; suportar, apoiar -, o conteúdo que nos traziam e a forma como traziam.

Em uma analogia com as ideias de Winnicott ([1963] 1983), lembrandonos de seu conceito sobre o desenvolvimento da capacidade de se preocupar; foi como se, ao estarmos ali, disponíveis, pudéssemos ter-lhes permitido investir com toda a sua hostilidade e descaso, para que depois pudessem chegar ao estado de nos perceber e se preocuparem com o que tinham causado em nós, e aí também cuidar, reparar e contribuir: ajudar a carregar e a colar os cartazes, dar tchau quando as coordenadoras iam embora, recebê-las com afetividade, procurar saber se nos sentimos rejeitadas por eles ou se a receptividade dos alunos da escola pública era melhor do que a receptividade deles. Cada um desses gestos, a nosso ver, iluminou uma nova perspectiva de se perceberem. Não sabemos o quanto, nem em quantos, e nem por quanto tempo, mas foi um bom começo.

Assim, a escola, como "quase um 'espaço' de transicionalidade" (Outeiral, 2005: 11), pode ser também um lugar de resistência, um lugar que se apresente ante o jovem, convocando-o a existir e a se expressar, mas, como tal, também não poderá ser invasiva, suscitando apenas a "reação" e impedindo a "ação". Como "espaço de resistência”, a escola possibilita ao jovem, através de sua ação, "transformá-la e ao mesmo tempo modificar-se a si próprio". Como observa Olgária Mattos (2005) em Sociedade: tolerância, confiança, amizade:

E-ducare significa "conduzir para fora de", evocando a ideia de itinerário e caminho, de um ponto a outro ou de um ao Outro. Tolerale, por sua vez, é levar, suportar e, também, combater. Neste caso, tolerar é esforço para desfazer ortodoxias, revelar dessemelhança no que parece homogêneo, a fim de que um possa ir ao encontro do Outro. Se a tolerância é algo que se aprende e ensina, seu lugar preferencial é a Escola (Matos, 2005: s/p). 
Clarificamos que, para efeito de exposição, suprimimos muito de partes importantes que se deram em cada um dos encontros, principalmente no que se refere ao terceiro encontro. A "ida" para a "experiência de transicionalidade" não se deu tão harmoniosa quanto pode ter parecido. Conteve riscos, receios "de não ser aceito na brincadeira”. Sentimentos e expressões por não se sentirem incluídos: angústia em não se sentirem ligados; momentos de solidão ao não poderem falar e não serem escutados. Mas deliberadamente, por uma questão de espaço, priorizamos o olhar mais próximo da "riqueza" que essa experiência parece ter representado.

\section{REFERÊNCIAS BIBLIOGRÁFICAS}

Abram, J. (2000). Transicionais, fenômenos. In: A linguagem de Winnicott-Dicionário das palavras e expressōes utilizadas por Donald W. Winnicott (pp. 253-265). Rio de Janeiro: Revinter.

Aurélio. Dicionário Século XXI 3.0. Versão eletrônica.

Cardoso de Oliveira, S. B. (2006). Indiferença, o esquecimento do humano: um estudo sobre a importância dos espaços de fala entre os jovens no contemporâneo. Dissertação de Mestrado. Curso de Pós-graduação em Psicologia, Universidade Federal do Rio de Janeiro.

Castro, L. R. de. (2003). Grupos de discussão com adolescentes: confrontando o "singular" na pesquisa e na prática clínica. Trabalho apresentado no III Congresso Norte Nordeste de Psicologia, João Pessoa, Paraíba, maio 2003. Mimeo.

. (2008). Conhecer, transformar(-se) e aprender: pesquisando com crianças e jovens. In: Castro, L. R. de \& Besset, V. L. (orgs.). Pesquisa-intervenção na infância e juventude (pp. 21-42). Rio de Janeiro: NAU.

Mattos, O. (2005). Sociedade: tolerância, confiança, amizade. Recuperado em 20 de julho de 2008. Disponível em <http://64.233.161.104/search?q=cache:7CwV3R_ 75 coJ:www.suigeneris.pro.br/filo_olgaria $>$.

Ortega, F. (2007). Selfe continuidade: entre Winnicott e William James. In: Bezerra, B. \& Ortega, F. (orgs.). Winnicott e seus interlocutores (pp. 126-165). Rio de Janeiro: Relume Dumará.

Outeiral, J. (2005). Trabalho com grupos na escola. In: Outeiral, J. \& Cerezer, C. O malestar na escola (pp. 9-22). Rio de Janeiro: Revinter.

Safra, G. (2005). Fenômenos e objetos transicionais. Realização Edições Sobornost. Aula ministrada na Universidade de São Paulo, DVD.

Symansky, H. \& Cury, V. (2004). A pesquisa intervenção em Psicologia da Educação e Clínica: pesquisa e prática psicológica. Estudos de Psicologia, 9 (2), 355-364. 
Winnicott, D. W. (1958). A capacidade para estar só. In: O ambiente e os processos de maturação: estudos sobre a teoria do desenvolvimento emocional (pp. 31- 37). Porto Alegre: Artes Médicas, 1983.

. (1959). O destino do objeto transicional. In: Winnicott, C.; Shepherd, R. \& Davis, M. (orgs.). Exploraçôes psicanalíticas: D. W. Winnicott (pp. 44-48). Porto Alegre: Artes Médicas Sul, 1994.

. (1960). Teoria do relacionamento paterno-infantil. In: $O$ ambiente e os processos de maturação: estudos sobre a teoria do desenvolvimento emocional (pp. 83-54). Porto Alegre: Artes Médicas, 1983.

. (1963). O desenvolvimento da capacidade de se preocupar. In: O ambiente e os processos de maturação: estudos sobre a teoria do desenvolvimento emocional (pp. 70-78). Porto Alegre: Artes Médicas, 1983.

. (1971a). O lugar em que vivemos. In: O brincar e a realidade (pp. 145-152). Rio de Janeiro: Imago, 1975.

. (1971b). Objetos transicionais e fenômenos transicionais. In: O brincar e a realidade (pp. 13-44). Rio de Janeiro: Imago, 1975.

(1971c). A localização da experiência cultural. In: O brincar e a realidade (pp. 133-143). Rio de Janeiro: Imago, 1975.

. (1971d). O brincar: a atividade criativa e a busca do eu (Self). In: O brincar e a realidade (pp. 133-143). Rio de Janeiro: Imago, 1975.

\section{NOTAS}

1 Este texto foi construído tendo como referência parte da dissertação de mestrado intitulada Indiferença, o esquecimento do humano: um estudo sobre a importância dos "espaços de fala" entre os jovens no contemporâneo. Dissertação de mestrado realizada no Programa de Pósgraduação em Psicologia da UFRJ, defendida em março de 2006 por Sonia Borges Cardoso de Oliveira. Agradecemos às Professoras Cláudia Amorim Garcia e Fátima Flórido Cesar as significativas contribuições durante a realização da referida dissertação, às quais estendemos esse artigo.

2 Este trabalho conjugou pesquisa e intervenção clínica, numa série planejada de encontros de grupos, cujo objetivo geral foi promover a discussão, a reflexão e a imaginação sobre aspectos da experiência na cidade. Realizado em 12 encontros, contou com a participação de seis alunas da $8^{\mathrm{a}}$ série, com idades entre 14 e 15 anos.

3 Subprojeto vinculado ao projeto de pesquisa "Infância, Juventude e Participação Social: a construção de subjetividades políticas no contemporâneo”, desenvolvido no âmbito do Nú- 
cleo Interdisciplinar de Pesquisa e Intercâmbio para a Infância e Adolescência Contemporânea (NIPIAC/UFRJ), sob a coordenação da Profa Lucia Rabello de Castro.

4 O texto, de autoria de Consuelo Silva, Helena Villela e Renata Alves de Paula Monteiro, é fruto do trabalho de pesquisa realizado no âmbito do NIPIAC/UFRJ.

5 O texto, de autoria de Elaine Junken, Bruno Pizzi e Carlos H. M. Barbosa, é fruto do trabalho de pesquisa realizado no âmbito do NIPIAC/UFRJ.

6 Agradecemos a Conceição Firmina Seixas Silva, Daniela Assis, Juliana de Almeida Correa, Laura Ferreira e Renata Alves de Paula Monteiro que participaram da coordenação do trabalho com os jovens e trouxeram a experiência viva relatada neste artigo.

Recebido em 20 de julho de 2008 Aceito para publicação em 16 de junho de 2009 